Research Article

\title{
Surface Settlement Damage Model of Pile-Anchor Supporting Structure in Deep Excavation
}

\author{
Yuanxun Li D, Wuyu Zhang, Ningshan Jiang, and Hui Li \\ School of Civil Engineering, Qinghai University, Xining, China \\ Correspondence should be addressed to Yuanxun Li; liyuanxun.521@163.com
}

Received 24 June 2019; Accepted 24 January 2020; Published 15 February 2020

Academic Editor: Salvatore Grasso

Copyright (c) 2020 Yuanxun Li et al. This is an open access article distributed under the Creative Commons Attribution License, which permits unrestricted use, distribution, and reproduction in any medium, provided the original work is properly cited.

In damage mechanics, the deep excavation of soil is a process of damage development, and soil failure can be considered a process of continuously transforming undisturbed soil to damaged soil. Therefore, this study considered the occurrence of soil damage during the pit excavation, established a soil damage model, damage evolution equation, and soil damage constitutive relationship, and then deduced a calculate model of the pile displacement under the consideration of soil damage. Based on the principle of the stratum loss method, the surface settlement around a deep excavated pit was assumed as a skewed distribution curve, and the surface settlement of the pile-anchor supporting pit was solved. Based on this established method, finite element analysis software was used to calculate the surface subsidence for a field case, and the numerical results were compared with monitoring data in the field. The results revealed that, to a certain extent, soil damage affected the distribution of surface settlement in excavated pits. With the development of soil damage, the mechanical properties of soil gradually decreased, which led to increased surface settlement and changes in the direction of the excavation pit. Because soil damage is an important factor causing surface settlement, it is meaningful to consider soil damage when calculating the surface settlement in the deep excavation of pits.

\section{Introduction}

In deep excavations, the deformation of the supporting structure and the ground subsidence interact with and restrict each other. Research on the deformation of the supporting structure is the basis of ground subsidence research. Moreover, extensive research has been conducted on the displacement of the supporting structure of deep excavations under different conditions, and useful conclusions have been drawn [1-4].

The accurate prediction and calculation of surface settlement around a deep excavation pit are important for the safe and smooth development of a deep excavation project. Thus, different prediction methods and theories have been proposed [5-8]. In 1969, Peck proposed a method of estimating the surface subsidence in relation to the soil properties and excavation depth using engineering measurements. Referring to Peck and Schmidt's theory, Xueyuan Hou (Tongji University, Shanghai, China) developed the formation loss method deriving from the triangular settlement formula to estimate the ground tunnel settlement of shield tunnels. These widely used methods derive from elastoplastic mechanics and the traditional theory of soil mechanics, and the soil in these studies is considered ideal undisturbed soil.

Based on engineering practice and experimental research, various studies have pointed out $[9,10]$ that it is unreasonable to describe the mechanical properties of damaged materials using the constitutive relationship of nondestructive materials. During the excavation of a foundation pit, the soil is damaged, and the soil behind the wall is no longer ideally undisturbed. Hence, the actual soil can be considered the combination of ideal undisturbed and completely damaged soil. Soil deformation occurs through the transformation of undisturbed soil to damaged soil [11]. In this situation, the soil mechanical properties are determined by the synthesis of the properties of the two soil types. Shen [12] first applied damage theory to the investigation of soil constitutive 
relationships. By applying the damage theory to soil mechanics, he established a basic framework of a soil model based on damage mechanics. Using the basic principles of irreversible thermodynamics and the theory of internal variables, Zhao et al. [10] established the evolution equations of these variables by introducing mechanical variables to simulate the damage state of materials and thus established a series of soil damage models. Shi et al. [13] introduced the damage and rheological properties of soil in the elastoplastic constitutive model of a double yield surface proposed by Zongze and experimentally investigated the variation of the mechanical properties of undisturbed soil and remolded soil. Then, they used the finite element method to analyze the settlement deformation of a soft soil foundation; however, the constitutive model was complex, and the parameters were difficult to obtain. Referring to the improved Zhujiang Shen damage model, Xiong [14] carried out finite element analysis on Biot's consolidation damage for a soft soil foundation. Li et al. [15] introduced structural damage variables for structural soft soils and established an extended elastoplastic damage model based on the theory of rock-soil damage mechanics and the classical modified Cambridge model. He et al. [16] introduced the concept of damage ratio to the settlement calculation of soft soil foundations. They proposed a method to determine the deformation modulus of soft soil foundations by considering the damage evolution and obtained reasonable and feasible calculation results.

Therefore, based on previous studies, this study attempted to select appropriate damage variables based on soil mechanics theory and establish a soil damage model, damage evolution equation, and soil damage constitutive relationship to develop a body displacement model for the pile in consideration of soil damage. The principle of the formation loss method was deduced and further applied to solve the ground settlement of a pile-anchor support structure in a deep excavation. Finally, verification analysis was carried out.

\section{Soil Damage Model of Deep Excavation}

From the viewpoint of damage mechanics, the process of deep excavation is a process of damage development. The failure of soil can be considered a process of continuously transforming undisturbed soil to damaged soil. The soil around a deep excavation includes undisturbed soil and damaged soil; therefore, the soil stress and elastic modulus combined with strain equivalence can be assumed as follows:

$$
\begin{aligned}
& \sigma=(1-d) \sigma_{i}+d \sigma_{d}, \\
& E=(1-d) E_{i}+d E_{d}, \\
& \sigma=\left[(1-d) E_{i}+d E_{d}\right] \varepsilon,
\end{aligned}
$$

where $d=$ damage variable, $\sigma_{i}=$ stress of undisturbed soil, $E_{i}=$ elastic modulus of undisturbed soil, $\sigma_{d}=$ stress of damaged soil, and $E_{d}=$ elastic modulus of damaged soil.
2.1. Determination of Damage Variables. Owing to the structural nature of the soil, its deformation consists of two parts: elastic and plastic. According to the concept proposed by Shen [17], the damage ratio is used to represent the damage of the soil, that is, the damage variable $d$, which represents the proportion of damaged soil in the entire soil. Therefore, the soil characteristic parameter can be expressed as the weighted average of the two:

$$
S=(1-d) S_{i}+d S_{d},
$$

where $S_{i}$ and $S_{d}$ represent the same characteristic indices of undisturbed and damaged soil, respectively.

2.2. Damage Evolution Equation. This study adopted the formula proposed by Shen [17] (equation (5)) to describe the evolution of soil damage. It is assumed that the damage variable $d$ is the strain function of the soil; $m$ and $n$ are the damage parameters; $m$ can be determined by the curve of the compressed undisturbed soil.

$$
\begin{aligned}
& d=1-e^{\left(-m \varepsilon_{v}-n \varepsilon_{s}^{2}\right)}, \\
& m=\frac{1}{\varepsilon_{v}} \cdot \ln \left(\frac{K_{i} \varepsilon_{v}-\sigma_{v d}}{\sigma_{v}-\sigma_{v d}}\right), \\
& n=\frac{1}{\varepsilon_{s}^{2}} \cdot \ln \left(\frac{2 G_{i} \varepsilon_{s}-\sigma_{s d}}{\sigma_{s}-\sigma_{s d}}\right) .
\end{aligned}
$$

Under isotropic compression conditions, $\varepsilon_{s}=0$; therefore, $m$ can be expressed as equation (6). Moreover, $n$ can be determined from the unconfined compression curve, under undrained conditions, and then $\varepsilon_{v}=0$. Furthermore, $n$ can be determined by calculating equation (7), and at the same time, it can be known from equation (10) because $\varepsilon_{v}=0$. Therefore, equation (7) can be simplified into the following equation:

$$
n=\frac{1}{\varepsilon_{s}^{2}} \cdot \ln \left(\frac{2 G_{i} \varepsilon_{s}}{\sigma_{s}}\right) .
$$

The stress and strain tensors are expressed by the ball and partial tensors, respectively. In equation (5), $\varepsilon_{v}$ is the body strain and $\varepsilon_{s}$ is the partial strain. Let $\varepsilon_{1}$ be the vertical strain of the soil and $\varepsilon_{3}$ be the strain in the horizontal direction; then, $\varepsilon_{2}=\varepsilon_{3}$. Thus, $\varepsilon_{v}=\varepsilon_{1}+2 \varepsilon_{3}$ and $\varepsilon_{s}=\left|\varepsilon_{1}-\varepsilon_{3}\right|$.

In equations (6) and (7), $K_{i}$ and $G_{i}$ denote the bulk modulus and shear modulus of the undisturbed soil, respectively. Additionally, it is assumed that the undisturbed soil is an elastomer; therefore, the following relationships hold:

$$
\begin{aligned}
K_{i} & =\frac{E_{i}}{3(1-2 \mu)}, \\
G_{i} & =\frac{E_{i}}{2(1+\mu)},
\end{aligned}
$$

where $E_{i}=$ elastic modulus of undisturbed soil and $\mu=$ Poisson's ratio for soil. 
For damaged soil, the soil characteristic parameters $\sigma_{v d}$ and $\sigma_{s d}$ can be expressed according to the Naylor and Domaschuk models, respectively, as follows:

$$
\begin{gathered}
\sigma_{v d}=\sigma_{0} e^{\left(\varepsilon_{v} / c_{c}\right)}-\sigma_{0}, \\
\sigma_{s d}=\frac{\varepsilon_{s}}{1 / 2 G_{0}+R_{f} \varepsilon_{s} / \sigma_{s f}},
\end{gathered}
$$

where $\sigma_{0}=$ initial stress of damaged soil, $c_{c}=$ volume compression index, $R_{f}=$ destruction ratio, $G_{0}=$ initial slope of the shear curve, and $\sigma_{s f}=$ damage stress, whose values were obtained from the literature [17].

2.3. Soil Damage Constitutive Relationship. The deformation process of the body is nonlinear. As mentioned above, the soil around a deep excavation can be considered a mixture of undisturbed soil and damaged soil. Therefore, the apparent stress of the soil can be expressed by equation (1), which is generalized to a tensor form as follows:

$$
\{\sigma\}=(1-d)\left\{\sigma_{i}\right\}+d\left\{\sigma_{d}\right\} .
$$

Furthermore, the incremental form is expressed as follows:

$$
\{\Delta \sigma\}=(1-d)\left\{\Delta \sigma_{i}\right\}+d\left\{\Delta \sigma_{d}\right\}-\left[\left\{\sigma_{i}\right\}-\left\{\sigma_{d}\right\}\right] \Delta d .
$$

According to the strain equivalence hypothesis, the incremental forms of the undisturbed and damaged soil's stress tensor can be expressed, respectively, as follows:

$$
\begin{aligned}
\left\{\Delta \sigma_{i}\right\} & =\left[D_{i}\right]\{\Delta \varepsilon\}, \\
\left\{\Delta \sigma_{d}\right\} & =\left[D_{d}\right]\{\Delta \varepsilon\},
\end{aligned}
$$

where $\left[D_{i}\right]$ and $\left[D_{d}\right]$ are the tangent stiffness matrices of the undisturbed soil and damaged soil, respectively.

Let us assume that the damage variable is a function of strain, as follows:

$$
\Delta d=\left\{\frac{\partial d}{\partial \varepsilon}\right\}^{T}\{\Delta \varepsilon\} .
$$

Moreover, the damage variable can also be obtained by equation (5), as follows:

$$
\Delta d=(1-d)\left[m\left\{\Delta \varepsilon_{v}\right\}+2 n\left\{\varepsilon_{s}\right\}\left\{\Delta \varepsilon_{s}\right\}\right] .
$$

By substituting equations (14)-(16) into equation (13), the relationship between the stress increment and the strain increment can be expressed as follows:

$$
\{\Delta \sigma\}=[D]_{d}\{\Delta \varepsilon\},
$$

where $\left[D_{d}\right]$ is the tangent damage modulus matrix and is expressed as follows:

$$
[D]_{d}=(1-d)\left[D_{i}\right]+d\left[D_{d}\right]-\left[\left\{\sigma_{i}\right\}-\left\{\sigma_{d}\right\}\right]\left\{\frac{\partial d}{\partial \varepsilon}\right\}^{T},
$$

where the composition of $\left[D_{i}\right]$ and $\left[D_{d}\right]$ is the same and $\left[D_{i}\right]$ can be expressed as follows:

$$
\left[D_{i}\right]=\left[\begin{array}{cccccc}
K_{i}+\frac{4}{3} G_{i} & K_{i}-\frac{2}{3} G_{i} & K_{i}-\frac{2}{3} G_{i} & 0 & 0 & 0 \\
K_{i}-\frac{2}{3} G_{i} & K_{i}+\frac{4}{3} G_{i} & K_{i}-\frac{2}{3} G_{i} & 0 & 0 & 0 \\
K_{i}-\frac{2}{3} G_{i} & K_{i}-\frac{2}{3} G_{i} & K_{i}+\frac{4}{3} G_{i} & 0 & 0 & 0 \\
0 & 0 & 0 & 2 G_{i} & 0 & 0 \\
0 & 0 & 0 & 0 & 2 G_{i} & 0 \\
0 & 0 & 0 & 0 & 0 & 2 G_{i}
\end{array}\right]
$$

\section{Calculation Model of Pile Displacement}

For the interaction between the pile and the soil, there are many kinds of research methods according to different research directions; for example, Zhang et al. [18-20] used the hyperbolic model to describe the relationship between the pile-soil skin friction and the vertical relative displacement of a single pile and pile groups under vertical load. In the pile horizontal displacement calculation, the interaction between the pile and the soil is simplified as a series of discrete soil springs, and factors such as the soil's nonlinearity, stiffness variation, and stratification are considered. However, in the calculations, it is assumed that the soil properties do not change during the deep excavation process, but in fact, the process is accompanied by the occurrence of soil damage. Therefore, the soil-soil and soil-pile interactions cannot be represented by a single-spring model, as shown in Figure 1. The double-spring model proposed by Shen [17] can better reflect this relationship.

First, the following three assumptions were made to establish a computational model:

(1) The soil of the deep excavation is undisturbed prior to the excavation.

(2) The soil spring is a double-spring model, as shown in Figure 2.

(3) The soil above the excavation surface of the foundation pit is damaged, while the soil below the excavation surface is undisturbed.

Based on the above assumptions, during a deep excavation, the soil spring on the side of the excavation is eliminated with the formation of the excavation surface; that is, the earth pressure acting on the unexcavated soil is reduced. From the stress-strain relationship curve of the damaged soil [21] (Figure 3), it can be seen that the elastic modulus of the soil gradually decreases with the increase of the soil strain. Therefore, the elastic modulus of the soil can be used to describe the damage to the soil.

From equation (2), it is known that $E_{i}$ and $E_{d}$ are the elastic modulus of the undisturbed soil and damaged soil, 


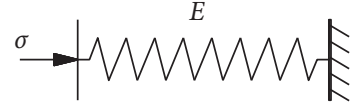

Figure 1: Single-spring model.

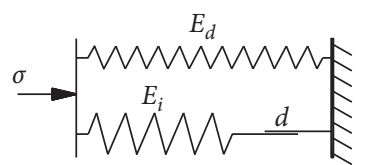

FIGURE 2: Double-spring model.

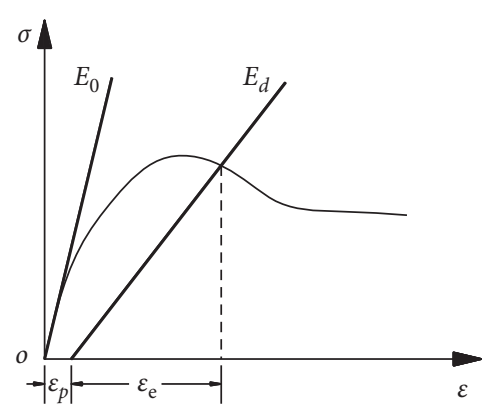

Figure 3: Stress and strain of damage soil.

respectively, where $E_{i}=E_{0}$, in which $E_{0}$ denotes the initial elastic modulus of the soil. Moreover, $E_{d}=0$, and equation (2) can be written as follows:

$$
E=(1-d) E_{i}
$$

In equation (21), the damage of the soil is reflected by the corresponding decrease $(1-d)$ in the elastic modulus of the soil as the strain increases. The equivalent diagram of the interaction between the piles and the soils is shown in Figure 4.

Based on the results obtained by the previous study of one of the authors [22], the mixed method was used to calculate the horizontal displacement of the supporting piles. The calculation process of the mixed method considers the soil damage. Upon analysis, it was revealed that the damage of the soil leads to the constant change of the elastic modulus of the soil, which is reflected in the change of the soil spring stiffness matrix.

\subsection{Nonlinear Equations of Overall Structural Equilibrium}

$$
[K]\{\delta\}-\{P\}=0,
$$

where $[K]=$ overall stiffness matrix of the structure, $\{\delta\}=$ vector of all node displacements, and $\{P\}=$ vector of all node loads.

\subsection{Incremental Load}

$$
\left\{\Delta q_{i}\right\}=\left\{\Delta P_{i}\right\}+\left\{F_{i}\right\}+\left\{T_{i}\right\},
$$

where $\left\{\Delta q_{i}\right\},\left\{\Delta P_{i}\right\},\left\{F_{i}\right\}$, and $\left\{T_{i}\right\}$ are the load increments corresponding to the calculation conditions, earth pressure

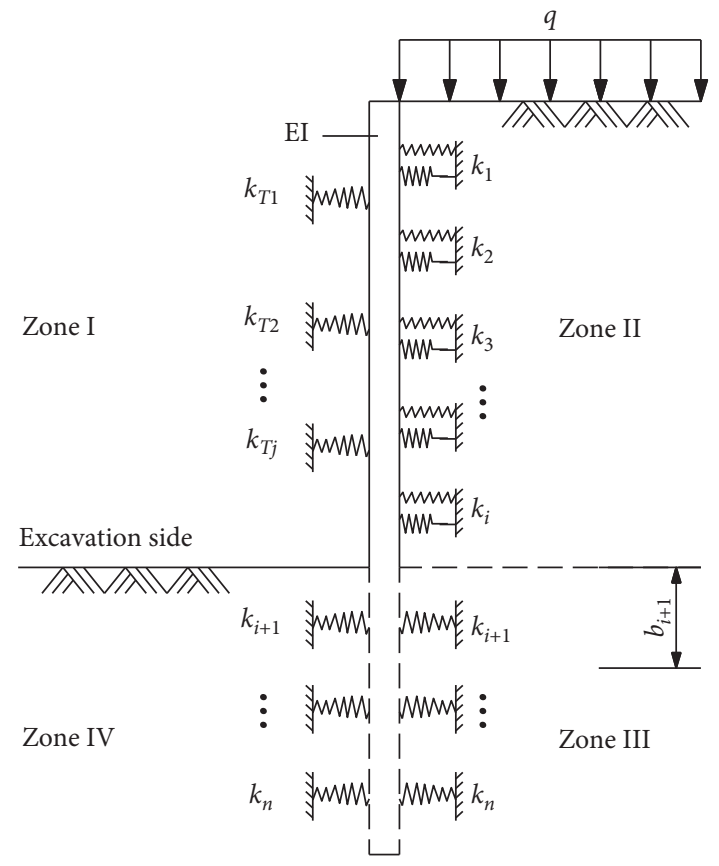

FIGURE 4: Soil spring equivalent diagram.

increment, elimination of the soil spring force, and bolt prestress, respectively.

3.3. Structural Overall Stiffness Matrix. The overall stiffness matrix of the structure consists of the residual soil spring stiffness matrix $\left[k_{i}\right]$ after the excavation, bolt stiffness matrix $\left[k_{T}\right]$, and row pile stiffness matrix $\left[K_{z}\right]$. Here, the row pile stiffness is considered the constant stiffness EI.

$$
\left[K_{i}\right]=\left[k_{i}\right]+\left[k_{T}\right]+\left[K_{z}\right] \text {. }
$$

Here, when considering the soil damage, $\left[k_{T}\right]$ and $\left[K_{z}\right]$ remain unchanged and only $\left[k_{i}\right]$ changes. Hence, based on the discussion in the previous section, it is assumed that the deep excavation is divided into four parts, as shown in Figure 4, and thus, the equivalent soil springs can be divided into four categories: the soil spring eliminated on the excavation side (zone I), the spring of the damaged soil acting on the pile above the excavation surface (zone II), the earth spring acting on the pile body below the excavation face (zone III), and the soil spring on the pile below the side of the excavation face (zone IV).

Amongst them, the soils in zones I, III, and IV are undisturbed soils. Therefore, the soil spring stiffness matrix can be generated by the soil springs obtained according to the Boussinesq solution.

The deformation displacement $\delta$, the soil's initial elastic modulus $E_{0}$, and Poisson's ratio $\mu$ are calculated.

Zone II consists of damaged soil, and its elastic modulus constantly changes. Therefore, the spring stiffness matrix of the soil in zone II can be solved as described below.

By substituting equation (21) in $k_{i}=\left(F_{i} / \delta\right)=\left(\left(b_{i} E\right) /\left(1-\mu^{2}\right) \omega\right)$, the soil spring stiffness coefficient can be expressed as follows: 


$$
k_{i}=\frac{b_{i}(1-d) E_{0}}{\left(1-\mu^{2}\right) \omega} .
$$

The damage variable $d$ is calculated using equation (5) and substituted into equation (25), as follows:

$$
k_{i}=\frac{b_{i} e^{\left(-m \varepsilon_{v}-n \varepsilon_{s}^{2}\right)} E_{0}}{\left(1-\mu^{2}\right) \omega},
$$

where $b_{i}$ is the length of the pile length, that is, the depth of action for each equivalent soil spring, and $E_{0}$ is the initial elastic modulus of the soil, that is, the elastic modulus of the undisturbed soil prior to the excavation.

The stiffness coefficient of each damaged soil spring is obtained using equation (26). Then, the stiffness matrix $\left[k_{i}\right]_{d}^{e}$ of the damaged soil element in zone II is obtained and transformed into the overall damage stiffness matrix $\left[k_{i}\right]_{d}$. Finally, the overall stiffness matrix of the structure in consideration of soil damage is substituted into equation (24), as follows:

$$
\left[K_{i}\right]_{d}=\left[k_{i}\right]_{d}+\left[k_{T}\right]+\left[K_{z}\right] .
$$

3.4. Pile Displacement Calculation. By substituting the incremental load $\left\{\Delta q_{i}\right\}$ corresponding to the calculation condition and the corresponding overall stiffness matrix $\left[K_{i}\right]$ into equation (22), the node displacement $\left\{\delta_{i}\right\}$ under the load increment of the working condition is solved and the error of the calculation result is corrected.

After applying all loads of this working condition, the incremental displacement of the node $\left\{\Delta \delta_{i}\right\}$ can be calculated as follows:

$$
\left[K_{T}\right]_{i}\left\{\Delta \delta_{i}\right\}=-\left\{\Psi\left(\delta_{i}\right)\right\}=\left\{P_{i}^{\prime}\right\}-\left\{F\left(\delta_{i}\right)\right\},
$$

where $\left[K_{T}\right]_{i}=$ overall tangent stiffness matrix, $\left\{\Psi\left(\delta_{i}\right)\right\}=$ structural unbalanced force, $\left\{F\left(\delta_{i}\right)\right\}=$ structural restoring force, and $\left\{P_{i}^{\prime}\right\}=$ total load applied to the supporting structure under this working condition.

Convergence discrimination: if $\Delta \delta_{i} \leq \alpha \delta_{i}$, then the convergence is calculated and the iteration terminates; otherwise, the structural tangent stiffness matrix is continuously calculated according to the displacement and the iteration continues until the convergence criterion is satisfied; $\alpha$ is the specified displacement convergence tolerance and is considered as $0.1 \% \leq \alpha \leq 5 \%$.

The incremental displacement calculated above is superimposed onto the previous working condition. Thus, the total displacement of the current working condition is obtained, and thereby, we can obtain the displacement of the entire structure.

\section{Calculation of Surface Settlement outside of Pit}

Presently, the main methods for predicting the surface subsidence around the foundation pit are the Peck empirical curve method, formation loss method, reliability method, stability safety factor method, numerical analysis method, and time-space effect method [23]. Amongst them, the formation loss method [24] proposed by Xueyuan Hou has been extensively used.

\subsection{Calculation of Envelope Area $S_{p}$ of Support Structure Displacement Curve}

$$
S_{p}=\sum_{i=1}^{n} \delta_{u i} \Delta h,
$$

where $\delta_{u i}$ is the horizontal displacement $(\mathrm{mm})$ at any position of the supporting structure within the excavation range of the foundation pit and can be calculated using the formula given in the previous section and $\Delta h$ is the length of the microsegment $(\mathrm{m})$.

\subsection{Determination of Envelope Area $S_{w}$ of Pit Settlement} Curve. According to the basic principle of the stratum loss method, there exists an empirical relationship between the envelope area $S_{w}$ of the surface subsidence curve and the envelope area $S_{p}$ of the retaining structure's displacement curve:

$$
S_{w}=m S_{p},
$$

where $m$ is the empirical coefficient of area correlation and can take the following values [24]: $m=1.0$ is generally preferable for a deep underground diaphragm wall or column cast-in-place pile support structure; $m=1.0 \sim 1.2$ is preferable when the insertion ratio $h_{d} / h \leq 0.5$, according to statistical analysis results and experience; and $m=0.8 \sim 1.0$ is preferable when the insertion ratio is $h_{d} / h>0.5$.

4.3. Calculation of Ground Settlement. The surface settlement curve of the pit is assumed to be a skewed distribution curve, and the function is expressed as follows:

$$
\delta_{v}(x)=\frac{S_{w}}{(\sqrt{2 \pi}) w x} e^{\left(-\left[\ln \left(x / 2 x_{m}\right)\right]^{2}\right) /\left(2 w^{2}\right)},
$$

where $\delta_{v}$ is the surface settlement for any point outside of the pit $(\mathrm{mm}) ; x$ is the distance between the settlement point and the pit's edge $(\mathrm{m}) ; x_{m}$ is the horizontal distance between the maximum settlement point and the pit's edge $(\mathrm{m})$, which is $0.5 \sim 0.7 h$ for a soft foundation pit and $0.25 \sim 0.5 h[25]$ for a complex stratum with better soil quality; and $w$ is the empirical coefficient for the soft foundation pit, and its preferred value is $0.6 \sim 0.7$. For the abovementioned complex strata, the empirical coefficients can be obtained directly from equation (31), provided that the maximum settlement location $x_{m}$ is known. The process is described below.

The first derivative of $\delta_{v}(x)$ is obtained as follows:

$$
\delta_{v}^{\prime}(x)=e^{\left(-\left[\ln \left(x / 2 x_{m}\right)\right]^{2}\right) /\left(2 w^{2}\right)}\left(-\frac{S_{w}}{(\sqrt{2 \pi}) w} \cdot \frac{\left(1 / w^{2}\right) \ln \left(x / 2 x_{m}\right)+1}{x^{2}}\right) .
$$

Let $\delta_{v}^{\prime}(x)=0$, at this time, for $x=x_{m}$. By substituting this into equation (32), we obtain $w=0.83$. 


\section{Engineering Example Verification Analysis}

5.1. General Situation of Engineering Examples. Figure 5 illustrates the section profile of the retaining wall on the west side. For the deep excavation of a comprehensive residential building project, the excavation depth of the foundation pit is $11 \mathrm{~m}$ and the total support length is approximately $256 \mathrm{~m}$. The surrounding environment of the foundation pit is complex. Pile-row prestressed anchors and composite soil nails are used to support the foundation pit in segments. The west side of the foundation pit is relatively spacious and used as a green lawn area. In this study, the west side of the foundation pit was selected as the research object. Hence, the surface settlement of the foundation pit was calculated using the proposed method, and the obtained results were compared with actual monitoring observations.

The west side of the foundation pit is supported by row piles with prestressed bolts. The diameter of the row piles is $800 \mathrm{~mm}$, the spacing is $2 \mathrm{~m}$, and the strength grade of the concrete is C30. HRB400 steel bars with a diameter of $28 \mathrm{~mm}$, spacing of $2 \mathrm{~m}$, anchor hole aperture of $150 \mathrm{~mm}$, inclination of $10^{\circ}$, and prestressing force of $100 \mathrm{kN}$ were selected as the anchor materials. The other parameters are presented in Figure 5.

The soil layers in the depth range of the foundation pit excavation are complex and include miscellaneous fill, loess silt, pebble soil, silty clay, fine sand, silty silt, pebble, and other soil layers. The soil parameters are listed in Table 1. During the foundation pit excavation, the groundwater depth was approximately $20 \mathrm{~m}$.

5.2. PLAXIS Simulation Analysis. Considering that various existing finite element analysis and calculation software do not consider the damage to the soil mass, PLAXIS 2D was selected for calculating the engineering examples. PLAXIS can better simulate the excavation and supporting process and provide various soil constitutive models. In this study, the hardened soil model (HS), which can obtain more reliable simulation results, was selected for simulation and analysis.

For the pile-anchor retaining structure, the pile can be considered a diaphragm wall, according to the principle of equal stiffness, which is expressed as $b h^{3} / 12=\pi D^{4} / 64$. As described in Figure 5, the diameter of the pile was $800 \mathrm{~mm}$, the spacing between piles was $1.2 \mathrm{~m}$, and the equivalent thickness $h$ was $586 \mathrm{~mm}$. Here, the meaning of $h$ is different from the previous meaning. The reinforced concrete of the pile was assumed to be a linear elastic material. The anchor used a point-to-point anchor to simulate the free section, and the geogrid element was used to simulate the anchoring section. The soil nails were also simulated using geogrid elements.

The pit was rectangular and symmetrical along its width direction, so half size of the pit along its width direction was selected in this numerical analysis. The model dimension was $60 \times 30 \mathrm{~m}$ (width $\times$ depth). A 15-node triangular element was used to simulate the soil body, and a plane strain finite element model was established. The interface between the supporting structure and the soil was simulated by the contact surface unit, which was extended to approximately $1 \mathrm{~m}$ under the supporting structure. This allowed the model to fully deform so as to obtain a more accurate stress distribution. Moreover, it was assumed that the horizontal displacements of the left and right boundaries were zero. Displacement was allowed in the vertical direction, while the bottom boundary of the model was fixed. The influence of groundwater was not considered in the excavation area of the foundation pit. Medium roughness was set as the texture of the grids around the piles, anchors, soil nails, pit surfaces, and soil close to the excavation surface. The geometric model and generated mesh are presented in Figures 6 and 7 , respectively.

According to the actual construction conditions, the contour profiles of the grid deformation and settlement after the excavation are shown in Figures 8 and 9, respectively; the displacement is shown at 50-fold magnification. As shown in Figure 8 , the meshing was ideal and the deformation distribution was reasonable. Additionally, it can be seen that the surface settlement outside of the pit mainly occurred at the excavation depth of the foundation pit, at 1-2 times the distance from the edge of the pit. The surface settlement within the action range of the prestressed anchor was obviously smaller compared with that outside of the action range. This implies that the application of the prestressed anchor to the pile-anchor supporting structure of the deep excavation can improve the properties of the soil behind the pile and reduce the soil settlement. Finally, the soil settlement was adequately controlled within the excavation area that was twice as far from the pit's edge.

5.3. Monitoring Results. Combined with the construction progress of the foundation pit, the period of monitoring the surface settlement outside of the pit started from the beginning of the foundation pit excavation and terminated until the floor mat of the foundation pit was completed. The entire monitoring period was 164 days (June 28 to December 8). According to the actual construction conditions, five stages were considered for monitoring and analysis. The monitoring stages are presented in Table 2.

Figure 10 shows that, in the initial stage of the foundation pit excavation, the surface settlement outside of the pit was small, while the maximum settlement appeared close to the edge of the pit. As the pit was gradually excavated, the location of the maximum settlement gradually moved far away from the pit, and the maximum settlement gradually increased. After the foundation pit was excavated to the design elevation, the surface settlement outside of the pit continued to increase, but the rate relatively slowed down until the construction of the main floor in the foundation pit was completed. The settlement variation tended to be stable. The prestressed anchor had obvious control over the surface settlement outside of the pit, and particularly over the soil settlement within $5 \mathrm{~m}$ from the pit's edge. The surface settlement of the deep excavation with the pile-anchor supporting structure was approximately $2 \sim 3$ times the excavation depth of the foundation pit. The maximum 


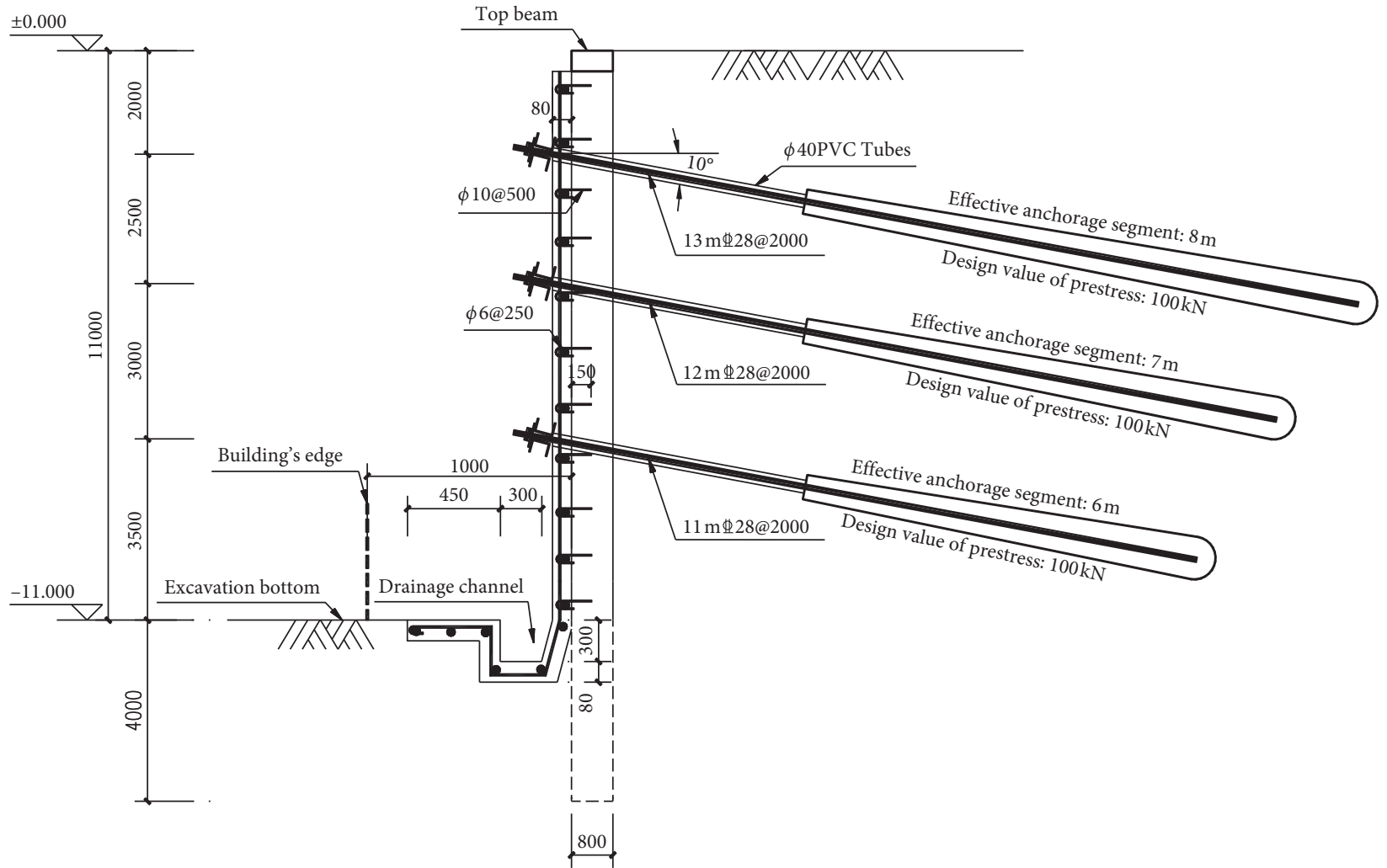

FIgURE 5: West side support section profile.

TABLe 1: Mechanical parameters of soil.

\begin{tabular}{|c|c|c|c|c|c|c|c|}
\hline Name of the soil layer & Miscellaneous fill & Loess silt & Pebble soil & Silty clay & Fine sand & Silty silt & Pebble \\
\hline Layer thickness $(\mathrm{m})$ & 1.8 & 7.2 & 1.6 & 4.8 & 2.5 & 3.0 & $>8.2$ \\
\hline Density $\gamma\left(\mathrm{kN} / \mathrm{m}^{3}\right)$ & 15 & 16 & 15 & 18 & 18 & 15 & 20 \\
\hline Friction angle $\varphi\left({ }^{\circ}\right)$ & 18 & 26 & 30 & 25 & 30 & 6 & 40 \\
\hline Cohesive force $c(\mathrm{kPa})$ & 10 & 18 & 0 & 19 & 4 & 10 & 0 \\
\hline Initial modulus of elasticity $E_{0}(\mathrm{MPa})$ & 23 & 25 & 34 & 28 & 59 & 18 & 172 \\
\hline Poisson's ratio $\mu$ & 0.2 & 0.26 & 0.21 & 0.28 & 0.22 & 0.32 & 0.27 \\
\hline
\end{tabular}

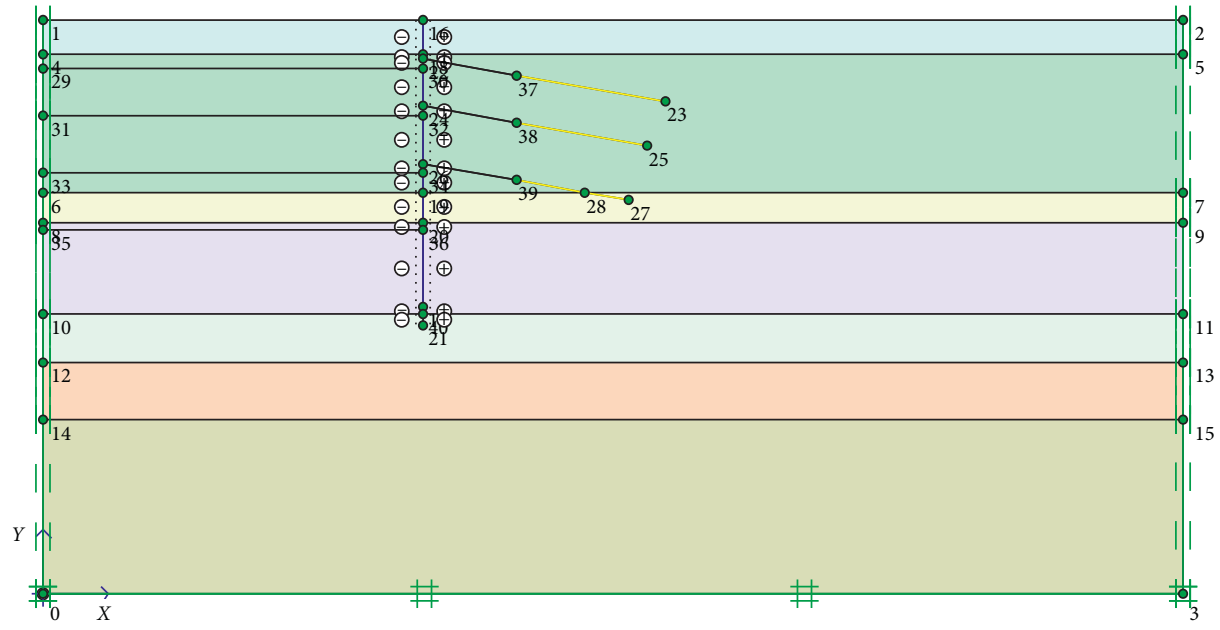

Figure 6: Computational geometric model. 


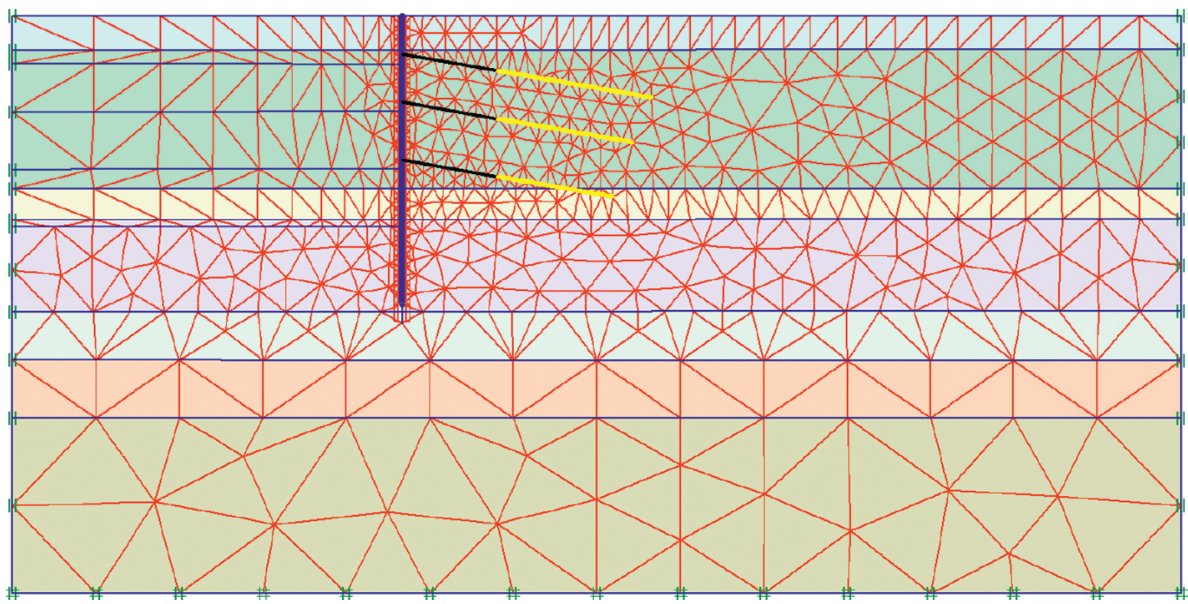

Figure 7: Finite element meshing

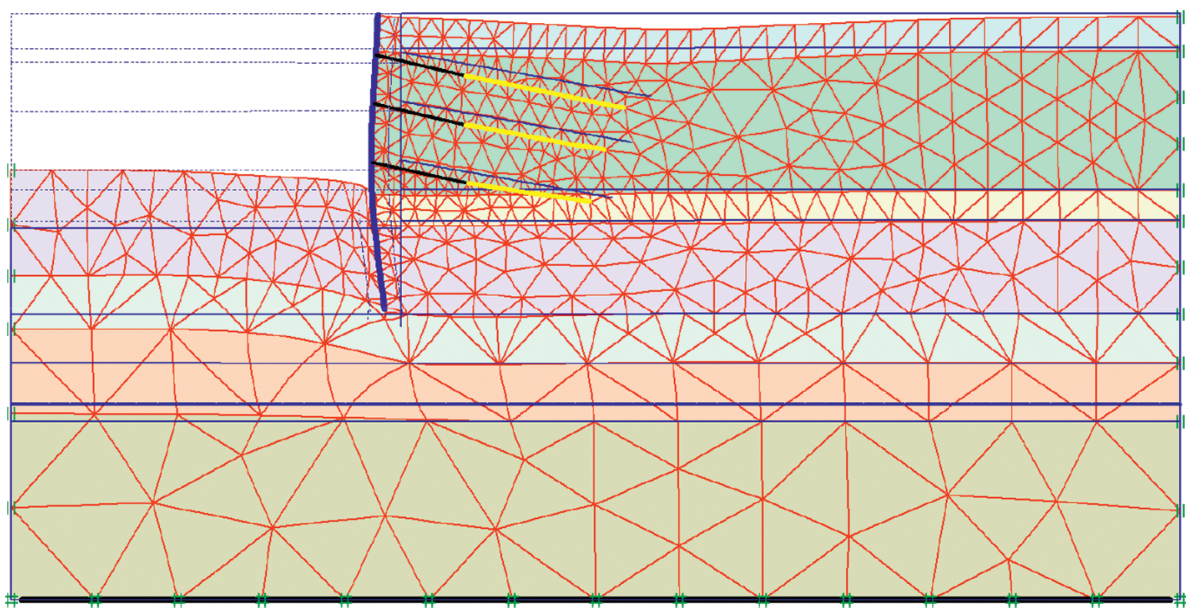

Figure 8: Mesh deformation.

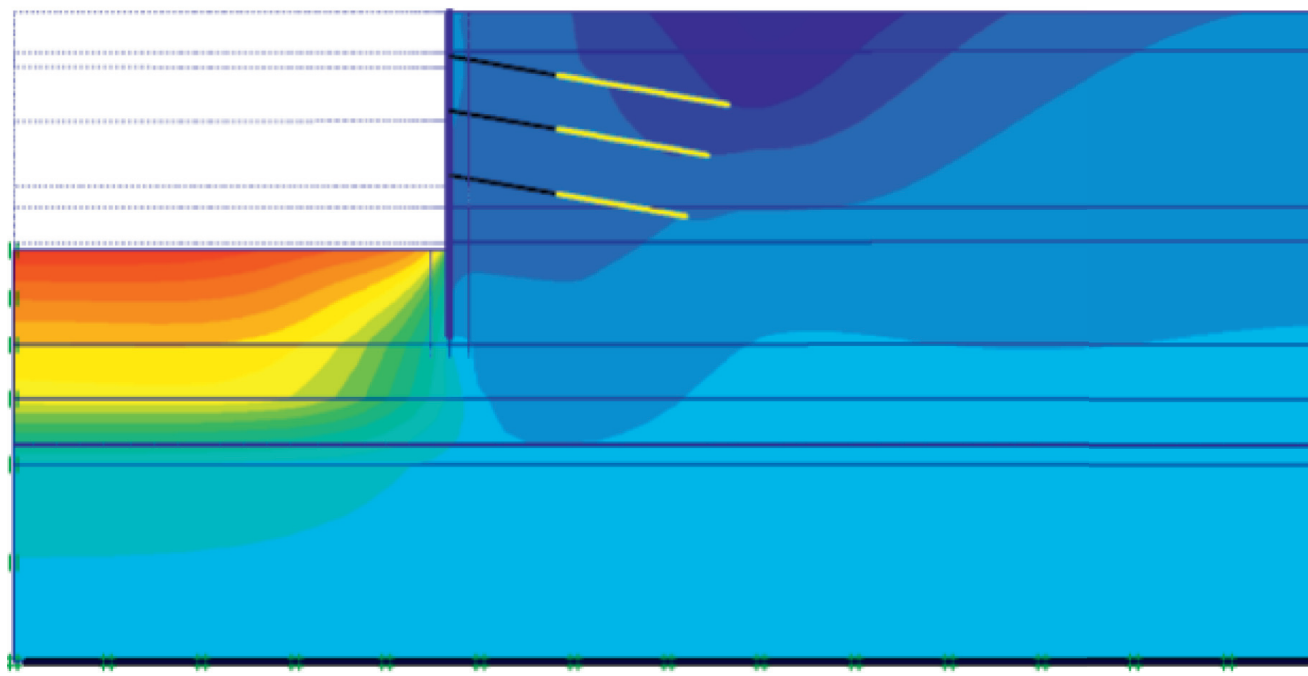

Figure 9: Vertical displacement nephogram. 
TABLE 2: Division of monitoring stages.

\begin{tabular}{lrcc}
\hline Monitoring stage & Construction conditions & Monitoring date & Settlement curve \\
\hline 1 & Excavating to $-3 \mathrm{~m}$, constructing anchor at $-2 \mathrm{~m}$ & $6.29-7.22$ & Figure $10(\mathrm{a})$ \\
2 & Excavating to $-5.5 \mathrm{~m}$, constructing anchor at $-4.5 \mathrm{~m}$ & $7.23-8.15$ & Figure $10(\mathrm{~b})$ \\
3 & Excavating to $-8.5 \mathrm{~m}$, constructing anchor at $-7.5 \mathrm{~m}$ & $8.16-9.18$ & Figure $10(\mathrm{c})$ \\
4 & Excavating to $-11 \mathrm{~m}$, followed by constructing foundation & $9.19-11.10$ & Figure $10(\mathrm{~d})$ \\
5 & Constructing building floor & $11.11-12.08$ & Figure $10(\mathrm{e})$ \\
\hline
\end{tabular}
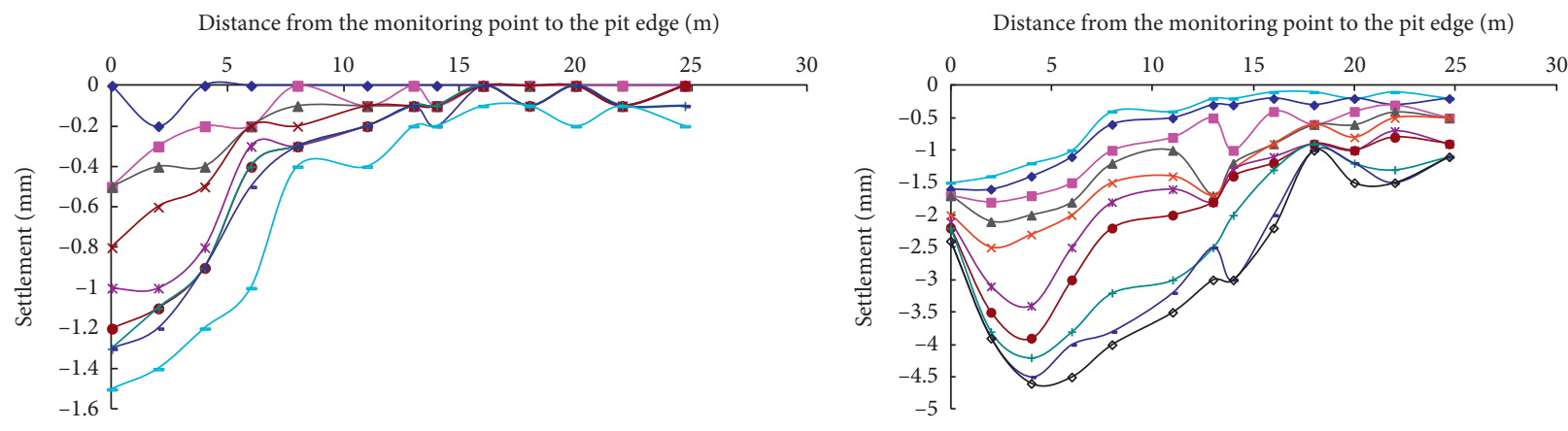

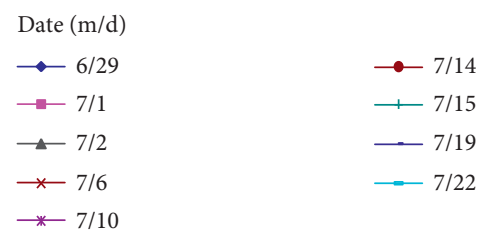

(a)

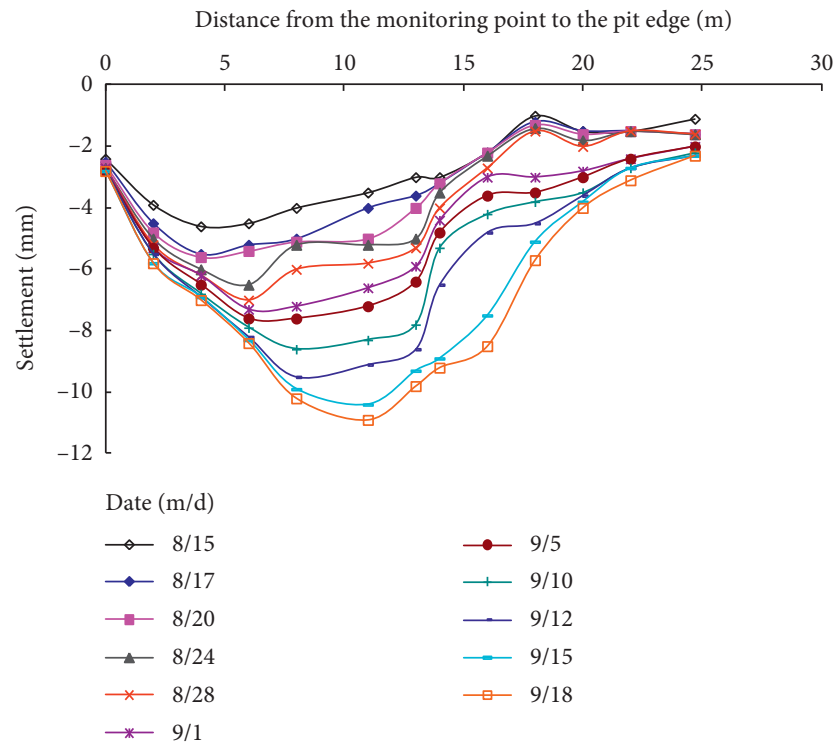

Date $(\mathrm{m} / \mathrm{d})$

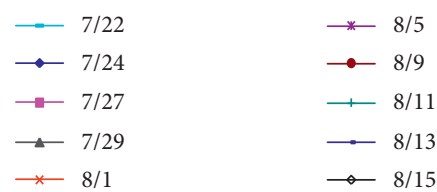

(b)

Distance from the monitoring point to the pit edge (m)
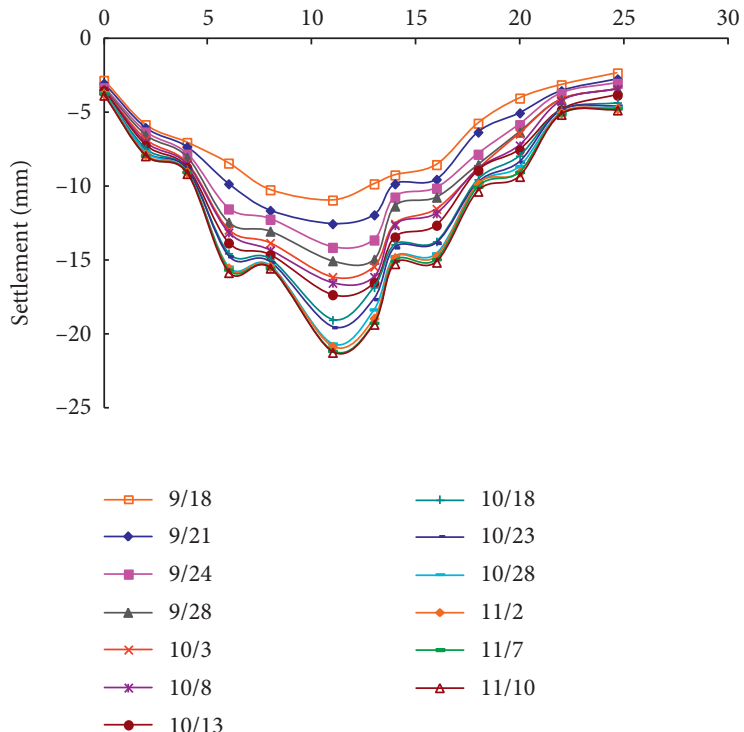

(d)

Figure 10: Continued. 


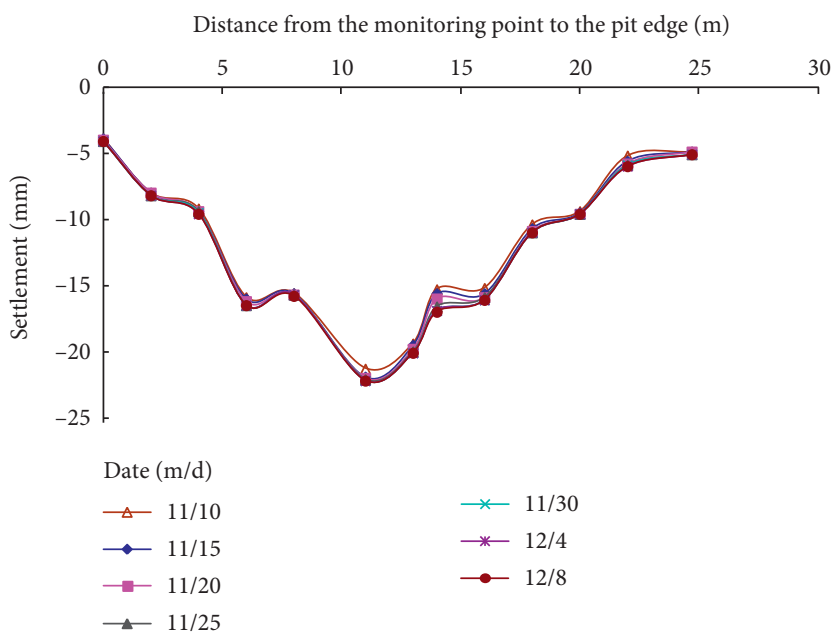

(e)

Figure 10: Variation curve of surface settlement during foundation pit excavation. (a) The first stage. (b) The second stage. (c) The third stage. (d) The fourth stage. (e) The fifth stage.

settlement point occurred at the depth of the foundation pit, which was approximately $1 \sim 1.5$ times the pit edge.

\section{Comparative Analysis}

The surface settlement outside of the pit was obtained by extracting the results obtained with the PLAXIS 2D software and substituting the parameters in Table 1 into the corresponding formulas presented in this paper. Additionally, the monitoring settlement data on December 8 were extracted from Figure 10(e). Figure 11 presents the comparison of settlement results obtained from these three methods.

By comparing the calculation and monitoring results, it was found that the surface settlement of the pit simulated in PLAXIS exhibited a normal distribution curve pattern, although a skewed distribution curve pattern was initially assumed. As can be seen from Figure 11, the measured surface settlement curve is generally consistent with the skewed distribution curve. Thus, it is feasible to describe the settlement of deep excavations using a skewed distribution curve. The maximum settlements obtained by the proposed method, PLAXIS, and measurements were $20.35 \mathrm{~mm}$, $16.60 \mathrm{~mm}$, and $22.10 \mathrm{~mm}$, respectively. The difference between the proposed method and the maximum settlement calculated by PLAXIS was approximately $8 \%$ and $25 \%$, respectively. The maximum settlement points obtained by the three methods were $10 \mathrm{~m}, 14.8 \mathrm{~m}$, and $11 \mathrm{~m}$ from the pit's edge, and the settlement values at $1 \mathrm{~m}$ from the pit's edge were $0.01 \mathrm{~mm}, 2.10 \mathrm{~mm}$, and $6.00 \mathrm{~mm}$, respectively. Additionally, the range of surface subsidence calculated using the proposed method was approximately $0 \sim 32 \mathrm{~m}$, while the range of surface subsidence in the PLAXIS simulation was approximately $0 \sim 34 \mathrm{~m}$. Both results are essentially equal to approximately $3 h$ ( $h$ is the excavation depth of the foundation pit), which is consistent with the influence range of surface subsidence in a soft soil area of $2 \sim 4 h$. This demonstrates that many factors affect the range of surface

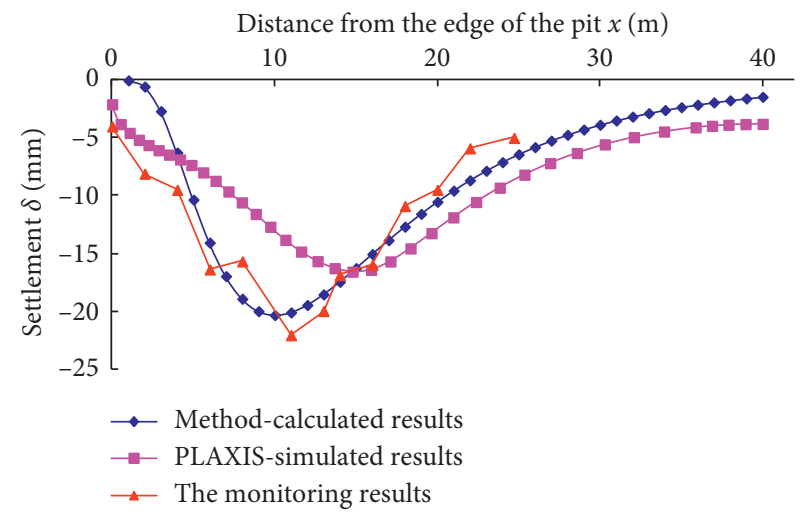

Figure 11: Surface settlement.

subsidence and that the change in the range of surface subsidence cannot be ignored in complex soil areas with poor soil properties.

In summary, the settlement value calculated using the proposed method was larger than the value obtained by the simulation. The maximum settlement point moved toward the pit's edge, and the calculated result is closer to the measured value; thus, it can better reflect the change of the actual surface settlement. The surface subsidence curve in this study does not consider the effect of overload that exists in most actual projects. Therefore, the overload of the foundation pit surface settlement in the complex environment outside of the pit must be further investigated.

\section{Conclusion}

This study considered the soil damage during a deep excavation from the viewpoint of damage mechanics. A deep soil excavation model considering soil damage was established according to existing knowledge, and the surface settlement curve was assumed. A calculation process for 
solving the surface settlement of a deep excavation was derived and applied to an actual engineering project. The following conclusions were drawn from this study:

(1) During the deep excavation process, the soil damage affects the distribution of surface settlement to a certain extent. With the development of soil damage, the mechanical properties of soil gradually decrease, which leads to increased settlement and changes in the direction of the foundation pit.

(2) The surface settlement distribution curve calculated using this method was more consistent with the measured value, compared with the normal distribution curve. This shows that it is reasonable and feasible to use a skewed distribution curve to describe the surface settlement outside of a deep excavation.

(3) Soil damage is an important factor causing surface settlement. Thus, it is necessary to consider soil damage when calculating the surface settlement of a deep excavation. The method proposed in this paper can be used as a reference when calculating the ground settlement for a deep excavation in areas with similar soil.

\section{Data Availability}

The data used to support the findings of this study are available from the corresponding author upon request.

\section{Disclosure}

The funders had no role in the design of the study; in the collection, analyses, or interpretation of data; in the writing of the manuscript; or in the decision to publish the results.

\section{Conflicts of Interest}

The authors declare no conflicts of interest.

\section{Acknowledgments}

This research was funded by China Qinghai Provincial Science \& Technology Department under grant numbers 2018-ZJ-933Q (http://www.qhkj.gov.cn/content/show/id/ 845) and 2018-ZJ-T01 (http://www.qhkj.gov.cn/content/ show/id/834).

\section{References}

[1] W. Zhang, R. Zhang, W. Wang, F. Zhang, and A. T. C. Goh, "A multivariate adaptive regression splines model for determining horizontal wall deflection envelope for braced excavations in clays," Tunnelling and Underground Space Technology, vol. 84, pp. 461-471, 2019.

[2] W. Zhang, A. T. C. Goh, and F. Xuan, "A simple prediction model for wall deflection caused by braced excavation in clays," Computers and Geotechnics, vol. 63, pp. 67-72, 2015.

[3] M. F. Ma'ruf and H. Darjanto, "Back calculation of excessive deformation on deep excavation," Procedia Engineering, vol. 171, pp. 502-510, 2017.
[4] A. Lim, P.-G. Hsieh, and C.-Y. Ou, "Evaluation of buttress wall shapes to limit movements induced by deep excavation," Computers and Geotechnics, vol. 78, pp. 155-170, 2016.

[5] C.-Y. Ou and P.-G. Hsieh, "A simplified method for predicting ground settlement profiles induced by excavation in soft clay," Computers and Geotechnics, vol. 38, no. 8, pp. 987-997, 2011.

[6] D. S. Liyanapathirana and R. Nishanthan, "Influence of deep excavation induced ground movements on adjacent piles," Tunnelling and Underground Space Technology, vol. 52, pp. 168-181, 2016.

[7] L. Ran, X. W. Ye, and H. H. Zhu, "Long-Term monitoring and safety evaluation of a metro station during deep excavation," Procedia Engineering, vol. 14, pp. 785-792, 2011.

[8] A. Lim and C.-Y. Ou, "Stress paths in deep excavations under undrained conditions and its influence on deformation analysis," Tunnelling and Underground Space Technology, vol. 63, pp. 118-132, 2017.

[9] T. Q. Yu and J. C. Qian, Damage Theory and its Application, National Defence Industry Press, Beijing, China, pp. 75-104, 1993.

[10] X. H. Zhao, H. Sun, and G. W. Luo, Damage Soil Mechanics, Tongji University Press, Shanghai, China, pp. 1-42, 2000.

[11] L. M. Hu and J. L. Pu, "Damage model of soil-structure interface," Rock and Soil Mechanics, vol. 23, no. 1, pp. 6-11, 2002.

[12] Z. J. Shen, "An elasto-plastic damage model for cemented clays," Chinese Journal of Geotechnical Engineering, vol. 15, no. 3, pp. 21-28, 1993.

[13] J. Y. Shi, W. B. Zhao, J. Gu et al., "Analysis of deformation of soft groud considering damage," Chinese Journal of Geotechnical Engineering, vol. 20, no. 2, pp. 1-5, 1998.

[14] C. X. Xiong, Structural property and damage numerical analysis of soft clay, Ph.D. thesis, Zhejiang University, Hangzhou, China, 2000.

[15] J. Z. Li, X. R. Zhu, and Y. H. Liu, "Elasto-plastc damage constitutive model and its application to structural soft soil," Journal of Zhejiang University (Engineering Science), vol. 44, no. 4, pp. 806-811, 2010.

[16] C. B. He, M. H. Zhao, B. H. Ma et al., "A nonlinear settlement computation method for soft foundation considering its structural characteristic," Building Structure, vol. 45, no. 14, pp. 82-86, 2015.

[17] S. S. Shen, "Wave interactions and X-ray crystallography," Nonlinear Topics in the Mathematical Sciences, vol. 3, pp. 247-275, 1993.

[18] Q.-q. Zhang and Z.-m. Zhang, "A simplified nonlinear approach for single pile settlement analysis," Canadian Geotechnical Journal, vol. 49, no. 11, pp. 1256-1266, 2012.

[19] Q.-q. Zhang, S.-w. Liu, S.-m. Zhang, J. Zhang, and K. Wang, "Simplified non-linear approaches for response of a single pile and pile groups considering progressive deformation of pilesoil system," Soils and Foundations, vol. 56, no. 3, pp. 473484, 2016.

[20] Q.-q. Zhang, S.-w. Liu, R.-f. Feng, and X.-m. Li, “Analytical method for prediction of progressive deformation mechanism of existing piles due to excavation beneath a pile-supported building," International Journal of Civil Engineering, vol. 17, no. 6, pp. 751-763, 2019.

[21] Z. D. Liu and S. E. Wang, "Mechanics description of the damage of structural soil," Soil Mechanics and Foundation Engineering, vol. 10, no. 3, pp. 1-6, 1996. 
[22] Y. P. Zhu and Y. X. Li, "Application of mixing method to calculation of row pile anchor support in deep excavation," Rock and Soil Mechanics, vol. 34, no. 5, pp. 1416-1420, 2013.

[23] X. Q. Li, P. T. Wang, and J. Zhang, "Calculation analysis of circumferencial surface settlement of soft soil foundation pit," Rock and Soil Mechanics, vol. 28, no. 9, pp. 1879-1882, 2007.

[24] G. B. Liu and W. D. Wang, Excavation Engineering Manual, China Architecture and Building Press, Beijing, China, 2009.

[25] J. J. Tong, M. N. Wang, L. Yu et al., "A study of the land subsidence around the deep excavation of the Chengdu subway station," Hydrogeology and Engnieering Geology, vol. 42, no. 3, pp. 97-101, 2015. 